\title{
Protection Coordination and Anti Islanding Protection Solution for Biomass Power Plant Connected on Distribution Network
}

\author{
Srete Nikolovski, Marko Vukobratović, Ljubomir Majdandžić \\ Power Engineering Department, Faculty of Electrical Engineering Computing and Information Technology, Osijek, \\ Croatia
}

\begin{tabular}{l} 
Article Info \\
\hline Article history: \\
Received Jun 2, 2016 \\
Revised Sep 12, 2016 \\
Accepted Sep 26, 2016
\end{tabular}

Keyword:

Anti islanding

Biomas power plant

Computer simulation

Distribution network

Protection devices

Time current curves

\begin{abstract}
Protection coordination as well as anti-island protection play significant role in the process of biomass power plant connection on the distribution network. Distribution generation island operation in Croatia is unacceptable according to the existing National grid code Paper presents a protection coordination of all passive protections used in the real biomass power plant and connected distriubution network feeder. Short-circuits three phase, two phase and single line to ground faults and generator islanding simulations have been performed and simulated in the time domain at the different network locations using DIgSILENT Power Factory software. The timecurrent plots coordination of protective devices are made using Smart PDC module in Easy Power Protector software tool.
\end{abstract}

Copyright (c) 2016 Institute of Advanced Engineering and Science. All rights reserved.

\section{Corresponding Author:}

Srete Nikolovski,

Department of Power Engineering,

Faculty of Electical Engineering,

Josip Juraj Strossmyer University of Osijek,

K. Trpimira 2B, 31000 Osijek, Croatia.

Email: srete.nikolovski@etfos.hr

\section{INTRODUCTION}

Before the integration of the renewable power plants to distribution network, it is necessary to make a study of coordination and setting of all protection devices to meet the conditions of selectivity, fast operation, reliability and the redundancy. Particularly important is the anti-islanding protection. In the literature, the problem of passive and active methods of protection of isolated operation is well elaborated [1-4].New methods of active protection especially for PV power plants are based on 3rd harmonic component of output current to diagnose an anti islanding [5]. Also, an algorithm which is a combination of slip mode frequency-shift (SMS) and reactive power versus frequency (Q-f) represents an active method forthe islanding phenomena detection [6]. A passive islanding detection scheme for both synchronous and inverter based distributed generations interfaced to a microgrid using Decision Tree method is presented in [7].

For synhronous generators, different new algorithms are investigated, for example in the paper [8], an algorithm that can detect the islanding condition based on load voltage using $\mathrm{d}$ and q-components of local load voltagehas been proposed. Interesting solution for anti-islanding protection was presented in [9], a new passive-based islanding detection method, according to change in $\partial V_{D G} \partial Q_{D G}$ index. Paper [10] presents a passive islanding detection method based on the change of the 5th harmonic voltage magnitude at the point of common coupling between thegenerator and the grid. connection. Protection coordination and integration of PV power plant in distribution network was well present in [11]. This paper will present protection coordination and anti islanding protection for biomass power plant using modified method from [10]. Criteria for overcurrent protection coordination were followed from Croatian National Grid code lit [12]. 


\section{TECHNICAL DESCRIPTION OF BIOMASS POWER PLANT}

Thebiomass power plant of 6.3 / 10 (20) kV of Slavonian timber industry, hereinafter Slavonia DI, is the cogeneration plant integrated into the distribution system of Croation distribution system operator-HEP ODS Elektra, the distribution area of SlavonskiBrod. The installed capacity of the plant is $\mathrm{Sn}=6 \mathrm{MVA}$, with nominal $\cos \varphi=0.85$, an active powerat the generator terminals is $\mathrm{P}=4.66 \mathrm{~kW}$. Generator is a synchronous, three-phase, rated voltage $U_{n}=6.3 \mathrm{kV}$, equipped with rotation contactless system of excitation and voltage regulation. The rated speed of generator is $n_{n}=1500 \mathrm{rev} / \mathrm{min}$ and efficiency for retesvakues is is $97 \%$. Cogeneration plant producesthermal energy from biomass for its own needs, and electricity for the needs of the surrounding consumers. The facility has a contract with HROTE- Croatian electricity market operator [12]. All system is modeled in the purchase of electricity (NN 63/12) as a privileged power producer in the category of power producer $1001 \mathrm{~kW}$ to $5000 \mathrm{~kW}$. The planned annual electricity produstion is 32000 MWh with the expected availability of $8200 \mathrm{~h}$ per year, and $40150 \mathrm{MWh}$ of thermal energy at the level of hot water $\left(160-180^{\circ} \mathrm{C}\right)$ and $17370 \mathrm{MWh}$ at the level of hot water $\left(90-110^{\circ} \mathrm{C}\right)$.

This plant belongs to the type of steam power plants with combined cycle in which fuel is burned in a steam boiler, and a prime mover is a steam turbine. In addition to generating electricity, it also generates steam, and indirectly, it generates the hot water used for heating and technological processes within the plant timber industry. Dueto the combined production of heat and electricity (cogeneration), a coefficient of fuel efficiency up to $90 \%$ is achieved. To allow a greater flexibility in operation, condensing turbines with controlled steam extraction are used. Such turbines enable a change inthe electricity and thermal power ratio depending on the load, and consist of high-pressure and low-pressure part. In the combined production, all steam supplied from the boiler first expands in the high-pressure condensation turbine. This steam is after expansion by the heat exchanger, which act as capacitorsexploited for the technological processes in the industry (heating, cooking and drying of wood mass), while the rest goes to the low pressure turbine. At the entrance into the low pressure turbine, a gate valve which regulates the amount of steam for expansion is positioned. Constant pressure of the steam can be maintained by changing the amount of steam (subtracting) via above mentionedvalvefor changing the steam through thelow pressure turbine, the amount of vapor in the high-pressure turbine is affected (Figure 1).

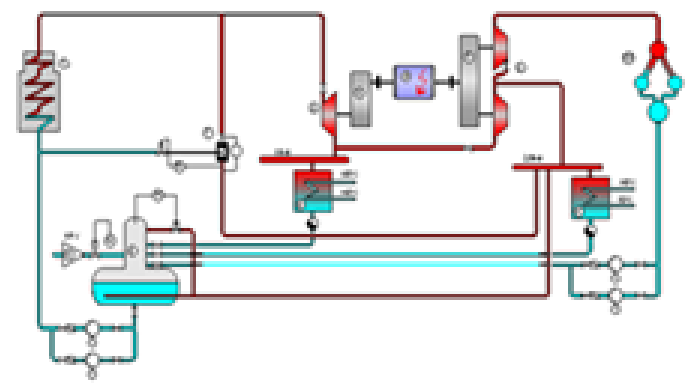

Figure 1. The Scheme of Cogeneration Plant with Condensing Turbine with Two Regulated Abstractions

where:

1) is steam boiler on wood waste (biomass)

2) is condensing turbine with two regulated abstractions

3) is reducer

4) is generator

5) is feed water tank

6) is chemical water treatment

7) is reducing cooling station

8) is high pressure thermal station

9) is low pressure thermal station

10) is air condenser

The plant's of own consumption cogeneration plant consists of the following independently powered subsystems with their own subsections on $0.4 \mathrm{kV}$ : boiler plant, landfill and transportation of biomass, turbine plant and electro-filter. On the basis of these data, generator power $6000 \mathrm{kVA}$ of rated voltage of $6.3 \mathrm{kV}$ was selected from INDAR manufacturer.The connection between the generator and the distribution network will be realized through transformers $6.3 / 10(20) \mathrm{kV} \pm 2 \times 2.5 \%$, enabling the future transition to the distribution voltage of $20 \mathrm{kV}$. Single line diagram of biomass power plant and utility TS 35/10 kV substation, $10 \mathrm{kV}$ distribution network and own industrial process using cogeneration is shown in Figure 2. 


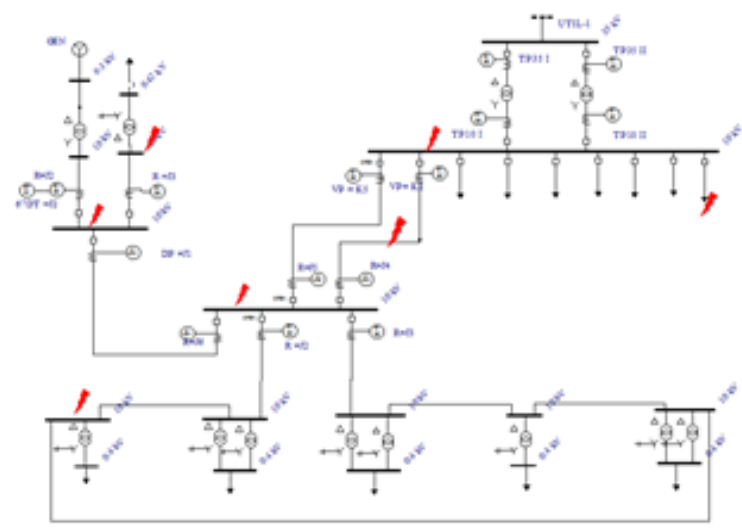

Figure 2. Single line diagram of power plant wiith own industrial consumers and distribution network

Generator data are given in Table 1:

Table 1. Generator Data

\begin{tabular}{lclcc}
\hline Generetor Data & $\begin{array}{c}\text { Type LSA-710- } \\
\text { K/4 }\end{array}$ & \multicolumn{1}{c}{ Reactences } & Unsaturate & Saturate \\
& $6000 \mathrm{kVA}$ & Synchronous Xd & $269 \%$ & $206,1 \%$ \\
Rated power & $6300 \mathrm{~V}$ & Synchronous Xq & $265,1 \%$ & $169.0 \%$ \\
Rated voltage & $549,9 \mathrm{~A}$ & Transient X'd & $27,4 \%$ & $25.9 \%$ \\
Rated current & 0,85 & Subtransient X"d & $19,1 \%$ & $16,7 \%$ \\
Power factor -cos $\varphi$ & $50 \mathrm{~Hz}$ & Subtransient X"d & $26,4 \%$ & $20,8 \%$ \\
Frequency & $1500 \mathrm{o} / \mathrm{min}$ & Inverse X2 & $22,2 \%$ & $18,5 \%$ \\
Rated Speed & $1800 \mathrm{o} / \mathrm{min}$ & Zero Xo & $11,1 \%$ & $9,7 \%$ \\
Max speed & $4 \mathrm{poles}$ & Stator lekageXl & $10,8 \%$ & $10,1 \%$ \\
Nr. of poles & 3 & Transient time comstant & $\mathrm{T}_{\mathrm{do}}$ & $1,93 \mathrm{~s}$ \\
Nr. of phases & $\mathrm{wye}$ & Subtransient time constants & $\mathrm{T}_{\mathrm{do}^{\prime \prime}}$ & $0,03 \mathrm{~s}$ \\
Connection & $40{ }^{\circ} \mathrm{C}$ & Subtransien time constant & $\mathrm{T}_{\mathrm{qo}}$ & $0,17 \mathrm{~s}$ \\
Temperature & $\mathrm{H} / \mathrm{H}$ & Transijent time constant & $\mathrm{T}_{\mathrm{d}^{\prime}}$ & $0,24 \mathrm{~s}$ \\
Class of isolation & $\mathrm{IC} 31$ & Subtransient time constants & $\mathrm{T}_{\mathrm{d}^{\prime \prime}}$ & $0,02 \mathrm{~s}$ \\
Type of cooling & & Subtransient time constant & $\mathrm{T}_{\mathrm{q}^{\prime \prime}}$ & $0,02 \mathrm{~s}$ \\
& & Armature time consant & $\mathrm{T}_{\mathrm{a}}$ & $0,08 \mathrm{~s}$ \\
& & DC resistance of stator at $20{ }^{\circ} \mathrm{C}$ & $\mathrm{R}_{\mathrm{a}}$ & $35,65 \mathrm{~m} \Omega$ \\
& & DC resistance of rotorat $20{ }^{\circ} \mathrm{C}$ & $\mathrm{R}_{\mathrm{f}}$ & $270,7 \mathrm{~m} \Omega$ \\
\hline
\end{tabular}

Network data consists of transformer data and distribution lines data given in Table 2 and Table 3

Table 2. Transformer Data

\begin{tabular}{ccccc}
\hline Voltage Level & $\begin{array}{c}\text { Rated Power } \\
(\mathrm{kVA})\end{array}$ & $\begin{array}{c}\text { Reletve Short Circuit } \\
\text { uk }(\%)\end{array}$ & $\begin{array}{c}\text { Connection } \\
\text { Number of } \\
\text { Units }\end{array}$ \\
\hline $10 / 0,4$ & 50 & 3.98 & Yzn5 & 2 \\
$10 / 0,4$ & 100 & od 3.8 do 4.03 & Yzn5 & 6 \\
$10 / 0,4$ & 160 & od 3.9 do 4.14 & Yzn5 & 5 \\
$10 / 0,4$ & 250 & od 3.81 do 4.4 & Yzn5 & 7 \\
$10 / 0,4$ & 400 & od 3.84 do 4.5 & Dyn5 & 12 \\
$10 / 0,4$ & 500 & 3.89 & Dyn5 & 1 \\
$10 / 0,4$ & 630 & od 3.9 do 5.76 & Dyn5 & 19 \\
$10 / 0,4$ & 1000 & 4 & Dyn5 & 10 \\
\hline
\end{tabular}


Table 3. Distributionline Data

\begin{tabular}{ccccc}
\hline Voltage Level(kV) & Type of Line & $\begin{array}{c}\text { Cross Section } \\
(\mathrm{mm} 2)\end{array}$ & $\begin{array}{c}\text { Ampacity } \\
(\mathrm{A})\end{array}$ & $\begin{array}{c}\text { Line Lengt } \\
8 \mathrm{~km})\end{array}$ \\
\hline & & Overhead line & 125 & 4,050 \\
10 & $\mathrm{Al} / \mathrm{Fe}$ & $3 \times 25$ & 170 & 1,770 \\
10 & $\mathrm{Al} / \mathrm{Fe}$ & $3 \times 50$ & 235 & 2,095 \\
10 & $\mathrm{Al} / \mathrm{Fe}$ & $3 \times 70$ & 290 & 9.730 \\
10 & $\mathrm{Al} / \mathrm{Fe}$ & $3 \times 95$ & 205 & 0,300 \\
& & & 255 & 0,100 \\
10 & IPO 13 & Cables & 290 & 0,480 \\
10 & IPO 13 & $3 \times 70$ & 380 & 0,380 \\
10 & IPO 13 A & $3 \times 120$ & 245 & 0,200 \\
10 & PHP 81 & $2 \times(3 \times 95)$ & 280 & 2,596 \\
10 & PP 41 A & $3 \times 95$ & 320 & 3,250 \\
10 & PP 41 A & $3 \times 120$ & 360 & 3,530 \\
10 & PP 41 A & $3 \times 150$ & 360 & 0,610 \\
10 & XHE 49 A & $3 \times 150$ & 335 & 1,212 \\
10 & XHE 49 A & $3 \times 150$ & 345 & 3,785 \\
10 & XHP 48 A & $3 \times 150$ & 315 & 4,980 \\
10 & XHP 48 A & $4 \times 150$ & & \\
10 & XHP 81 A & $3 \times 120$ & &
\end{tabular}

In accordance with the Technical conditions for connection of small power plants to the electric power system of Croatian Electricity power industry [1], when connecting power plants of total capacity up to and including $5000 \mathrm{~kW}$ protection system consists of:

a. Overcurrent stator protection I>

b. Overcurrent ground falult roor protection $\mathrm{I}_{\mathrm{E}}>$

c. Overvoltage protection $\mathrm{U}>$

d. Undervoltage protection $\mathrm{U}<$

e. Overfrequency protectiion $\mathrm{f}>$

f. Underfrequency protection $\mathrm{f}<$

g. Revers power protection $\mathrm{P}_{\mathrm{R}}>$

h. Unbalance protection Ii>

i. Diferential protection $\Delta \mathrm{I}>$

j. Termal proetction $\theta>$

k. Lost of exitation

1. Protection of exitation $\mathrm{I}_{\mathrm{f}}>$,

m. Overspeed protection $n>$

n. Underspeeed protection $\mathrm{n}<$

o. Antivibration protection

p. Protection of fault in secondary circuits

q. Cooling system protection
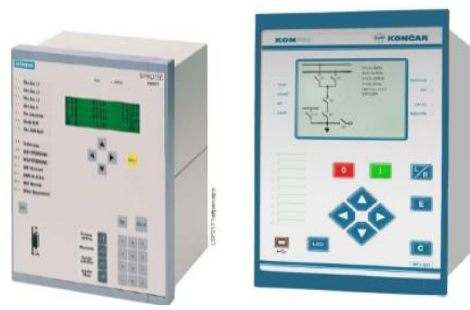

Figure 3. SIEMENS 7UM 621 Generator Protection and KONCAR RFX 652 Feeder Terminal Fields

Multifunctional microprocessor relay SIPROTEC 4 type 7UM621 is situatedin thebiomass power plant $10 \mathrm{kV}$ switching box $+\mathrm{J} 2$ to protect the generator of $6000 \mathrm{kVA}$ and block transformer of $6000 \mathrm{kVA}$, while the relays KONČAR RFX 632 are situated in all other switching boxes in power plant, substations and connection distribution network feeder as shown in Figure 3. 


\section{TIME DOMAIN FAULT ANALYSIS AND PROTECTION SIMULATION}

The simulations and calculations are performed by licensed software DIgSILENT Power Factory 14.1 versions. Malfunctions of three-phase short-circuit, two-phase short-circuit and single-line to groung faults were performed at locations:

a) Simulation of three-phase short-circuit and two-phase short-circuiton the cable between TS $35 / 10 \mathrm{kV}$ Brod 2 and switrchyardSlavonia DI 10(20)kV

b) Simulationofthree-phase short-circuit and two-phase short-circuiton switchyard Slavonia DI 10(20) kV

c) Simulationofthree-phase short-circuit and two-phase short-circuiton cable between switchyards Slavonia DI $10(20) \mathrm{kV}$ and the place of common coupling.

d) Simulation of three-phase short-circuit and two-phase short-circuiton $10 \mathrm{kV}$ busbar - place of common coupling.

e) Simulationof three-phase short-circuit and two-phase short-circuiton10 kV busbar-power plant block transformer

f) Simulation of three-phase short-circuit and two-phase short-circuiton $10 \mathrm{kV}$ busbar -power plant own consumption transformer

g) Simulation of three-phase short-circuit and two-phase short-circuit on $10 \mathrm{kV}$ busbar TS 10/0,4 kV impregnation

h) Calculation of single-line to groung faulton $10 \mathrm{kV}$ busbar of switchyard Slavona DI 10(20) $\mathrm{kV}$

i) Calculationof single-line to groung faulton cable between switchyardsSlavonia DI $10(20) \mathrm{kV}$ and the place of common coupling

j) Calculationof single-line to groung faulton $10 \mathrm{kV}$ busbar -the place of common coupling

k) Calculationof single-line to groung faulton $10 \mathrm{kV}$ busbar - power plant block transformer

1) Calculationof single-line to groung faulton $10 \mathrm{kV}$ busbar of power plant own consumption transformer

m) Calculation of single-line to groung faulton $10 \mathrm{kV}$ busbar TS 10/0,4 kV impregnation P Parquet factory

n) Calculation of single-line to groung fault on the beginning of the passive statement -VP 10-3 (Sv. Lovre) from TS 35/10 kV Brod 2

o) Calculationof single-line to groung faulton the end of the passive statement -VP 10-3 (Sv. Lovre) from TS 35/10 kV Brod 2

Due to the lack of space, in this paper only five cases of short circuit simulation will be presented:

a) SC1-three-phase short-circuit on cable between TS 35/10 kV Brod 2 and the switchyard Slavonia DI $10(20) \mathrm{kV}$

b) SC3 - three-phase short-circuiton busbars in RS Slavonia DI

c) SC7 - three-phase short-circuit on busbars in RS cogeneration plant Slavonia DI

d) SC11- three-phase short-circuit on $10 \mathrm{kV}$ busbars of power plant own consumption transformer At the timeinstant $\mathrm{t}=100 \mathrm{~ms}$ from the beginning of the simulation, the three-phase short-circuit of impedance $0 \Omega$ at the middle of $10 \mathrm{kV}$ cable between TS 35/10 kV Brod 2 and a switchyard Slavonia DI 10 (20) kV is performed:

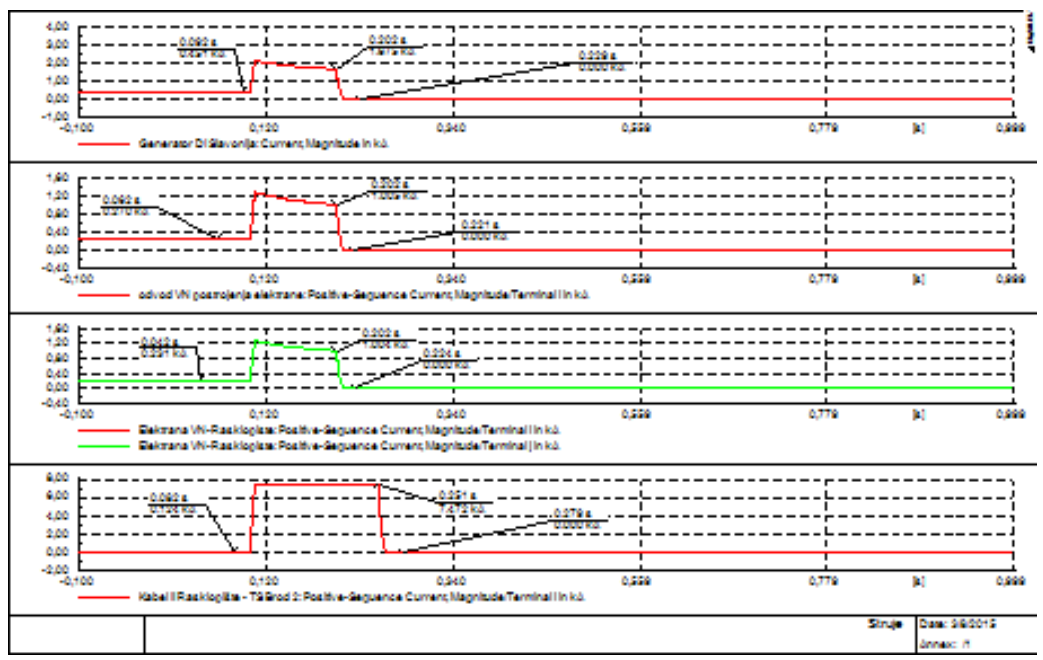

Figure 4. RMS Values of Currents During Short Circuit Simulation for Case SC1 
The first oscillogram in the Figure 4 shows the short-circuit contribution of the generator current. The second oscillogram shows the current in cable from the high-voltage outlet of power plant. The third oscillogram indicates the current between the separation of power plant and switchyard Slavonia DI 10 (20) $\mathrm{kV}$, and the fourth oscillogram denounces currentof the cable between TS $35 / 10 \mathrm{kV}$ Brod 2 and a switchyard Slavonia DI $10(20) \mathrm{kV}$. At time $\mathrm{t}=200 \mathrm{~ms}$ from the start of the simulation overcurrent protection of the relay in the field $\mathrm{J} 2$ trips generator. At time $\mathrm{t}=250 \mathrm{~ms}$ from the beginning of the simulation overcurrent protection I > relay PRIL 2000 in $10 \mathrm{kV}$ field K2 trips. TTC-Time Current Curves were plotted using for al protection devicesusing software tool [14] as shown in Figure 5.

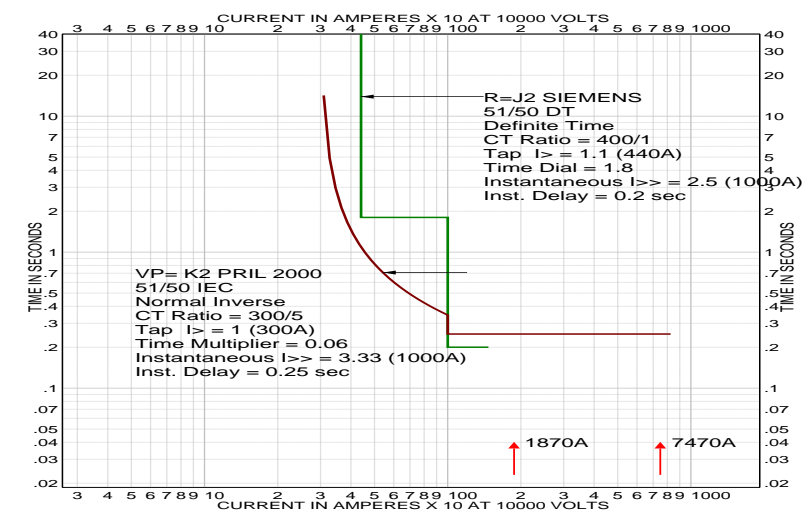

Figure 5. TCC Plots Of Overcurent Protection for Case SC1

At time $\mathrm{t}=100 \mathrm{~ms}$ from the beginning of the simulation, 3F-SC (three-phase short-circuit) of impedance $0 \Omega$ at $10 \mathrm{kV}$ busbar of switchyard Slavonia DI $10(20) \mathrm{kV}$ is performed.

The first oscillogram shows the short circuit contribution of the generator current.The second oscillogram shows the current in cable from the high-voltage outlet of power plant.The third oscillogram indicates the current between the separation of power plant and switchyard Slavonia DI 10 (20) kV, and the fourth oscillogram denounces current of the cable between TS 35/10 kV Brod 2 and a switchyard Slavonia DI 10 (20) kV as shown in Figure 6.

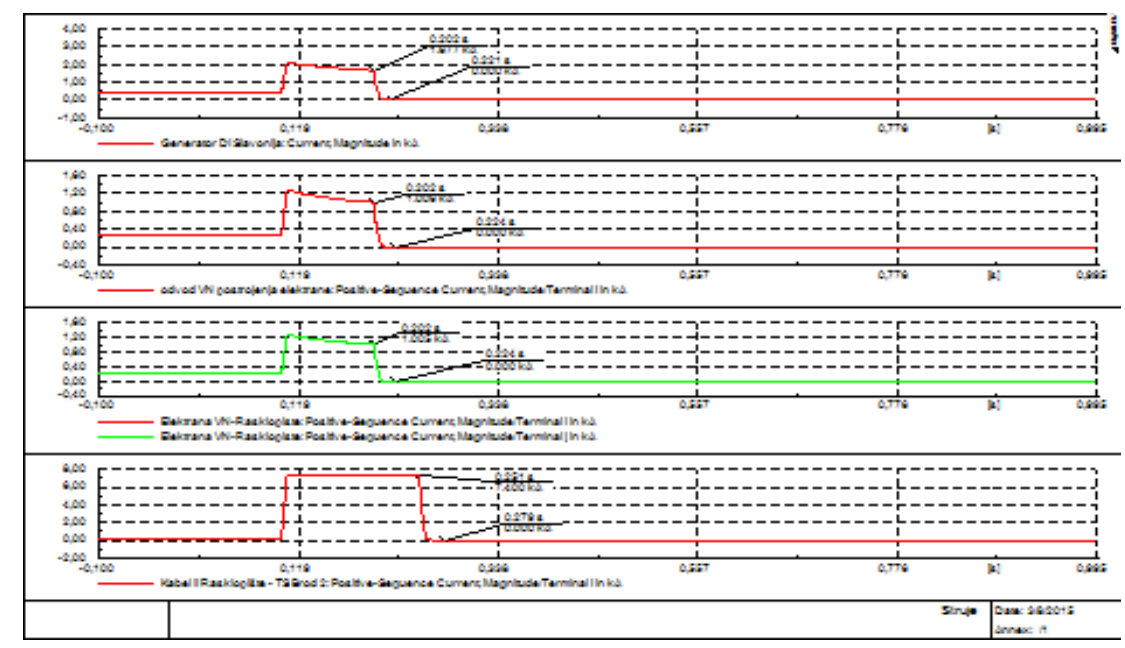

Figure 6. RMS Values of Currents During Short Circuit Simulation for Case SC3

At time $\mathrm{t}=200 \mathrm{~ms}$ from the beginning of the simulation, there is a switching event of a switch in the field $\mathrm{J} 2$ by tripping of the SIEMENS overcurrent generator. At time $\mathrm{t}=250 \mathrm{~ms}$ from the beginning of the simulation, non-directional overcurrent protection I >> relay PRIL 2000 in $10 \mathrm{kV}$ field K2 works through in 
TS 35/10 kV Brod 2 with the separation of the contacts of the respective switches, which causes the mutuall switching to exclude. t-I TCC curves are the same as for the previous case.

For the case SC7:

At time $\mathrm{t}=100 \mathrm{~ms}$ from the start of the simulation, 3F-SC (three-phase short-circuit) of the impedance $0 \Omega$ at $10 \mathrm{kV}$ busbar is generated - the place where the plant separates from the grid, Thecurrent of generator is shown by the first oscillogram in Figure 7. Currentin the cable of high voltage switch gear of the power plant is on the second oscillogram, whereas the current through the cable between the point of separation of the powerplant and switchyard Slavonia DI 10 (20) kV is on the third oscillogram. The fourth oscillogram shows current of thecable between TS 35/10 kV Brod 2 and a switchyard Slavonia DI 10 (20) $\mathrm{kV}$.

At time $\mathrm{t}=110 \mathrm{~ms}$ from the start of the simulation there is tripping of the overcurrent $\mathrm{I}>>$ relay in thefield J6 and the disconnection of the switch in the field J6 which isolated the fault from TS Brod 2. Atthe time $\mathrm{t}=200 \mathrm{~ms}$ from the start of the simulation there is aswitch disconnection in the field J2 by tripping of overcurrent protection generator, which causes a mutually isolated breakdown. At time $\mathrm{t}=201 \mathrm{~ms}$ from the start of the simulation there is excitation of an undervoltage member $\mathrm{U}<$, and $\Delta \delta$ member in the relay of the field J2.

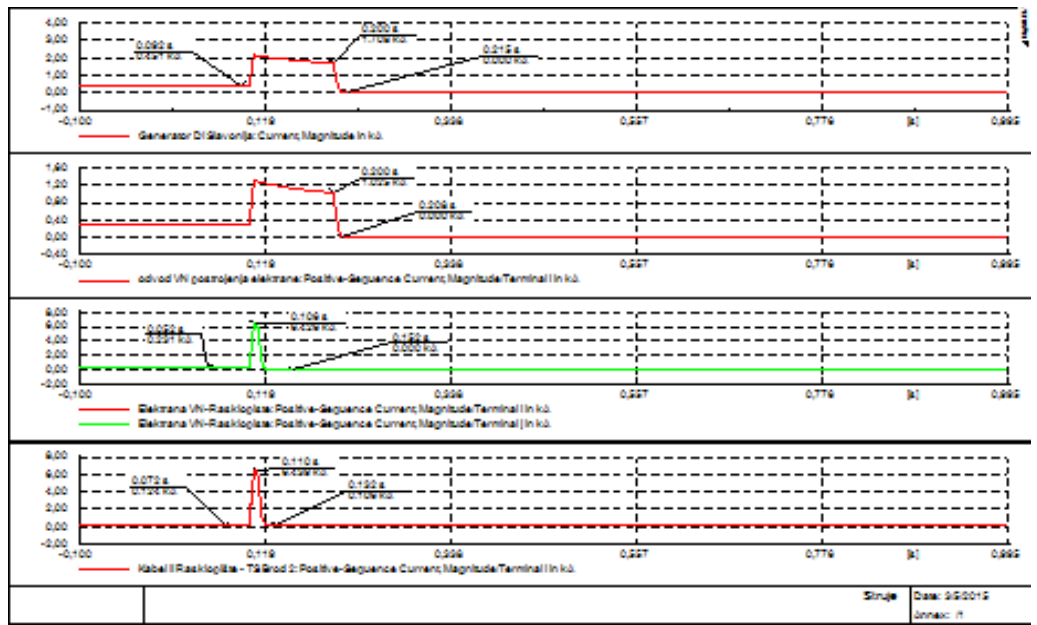

Figure 7. RMS Values of Currents During Short Circuit Simulation for Case SC7

TTC plots are presented in Figure 8

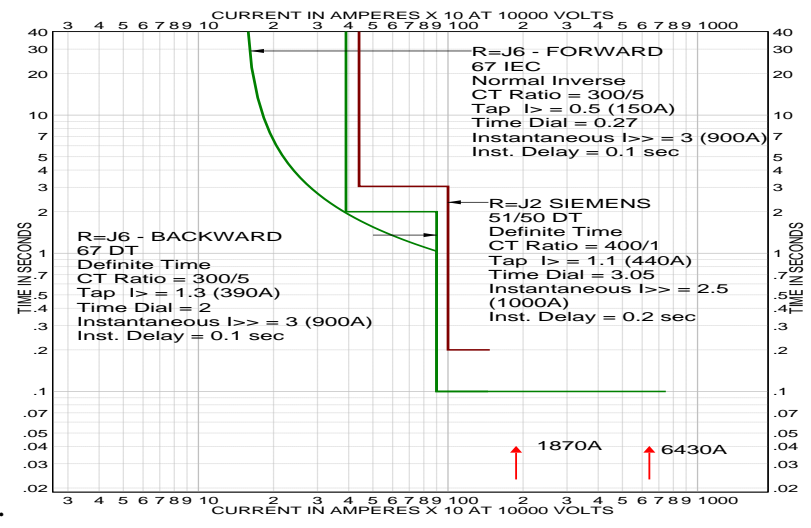

Figure 8. TCC Plots of Overcurent Protection for Case SC7

In the case SC11: 
At time $\mathrm{t}=100 \mathrm{~ms}$ from the start of the simulation $3 \mathrm{~F}-\mathrm{SC}$ of the impedance $0 \Omega$ at $10 \mathrm{kV}$ busbar unit transformer power is generated:

The current ofgenerator is presented on the first oscillogram in Figure 9. The current through the cable ofhigh voltage switchgear of powerplant is on the second oscillogram and current in the cable between the place where the plant separates and switchyard Slavonia DI 10 (20) kV is on the third oscillogram. The current through the cable between TS 35/10 kV Brod 2 and a switchyard Slavonia DI 10 (20) $\mathrm{kV}$ is on the fourth oscillogram.

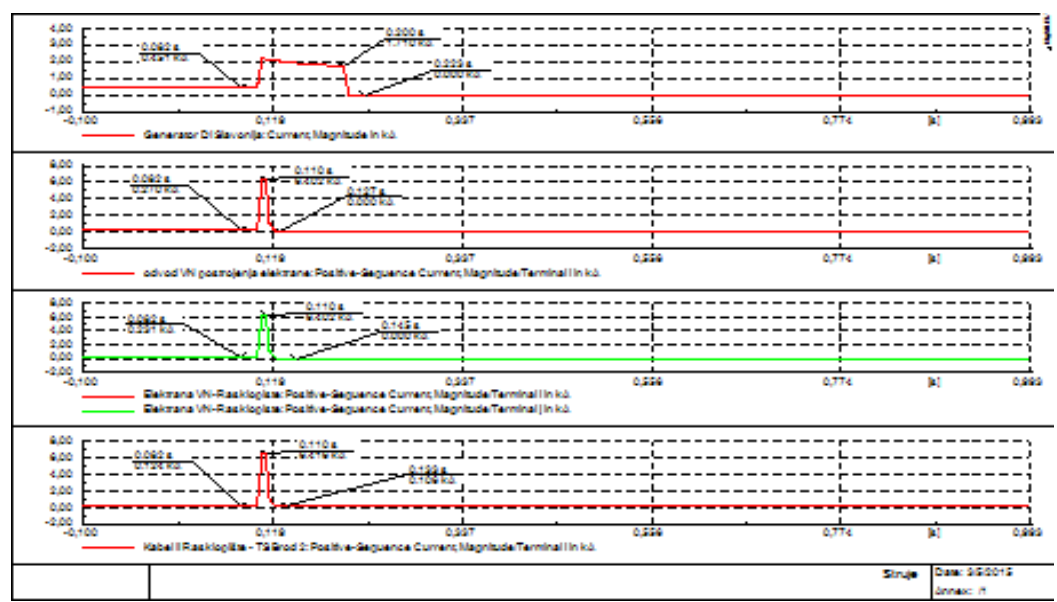

Figure 9. RMS Values of Currents During Short Circuit Simulation for Case SC11

At time $\mathrm{t}=110 \mathrm{~ms}$ from the start of the simulation there is tripping of the overcurrent $\mathrm{I} \gg$ relay in the field J6 and the disconnection of the switch in the field J6 which isolates the fault from the side of TS Brod 2. At time $\mathrm{t}=100 \mathrm{~ms}$ from the start of the simulation there is the switching event in the field $\mathrm{J} 3$ by tripping SIEMENS short-circuit protection transformer of own consumption and protection of the generator in the field $\mathrm{J} 2$, which is a mutually isolated breakdown. At time $\mathrm{t}=201 \mathrm{~ms}$ from the start of the simulation there is excitation of an undervoltage of member $\mathrm{U}<$, and $\Delta \theta$ member of the relay in the field $\mathrm{J} 2$.

TTC plots are presented in Figure 10

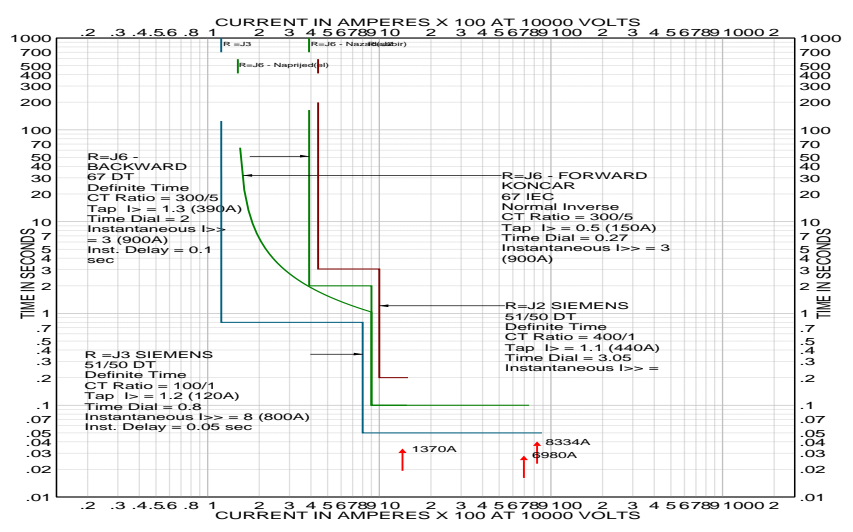

Figure 10. TCC Plots of Overcurent Protection for Case SC11

\section{ANTI-ISLANDING PROTECTION}

The protection system of distributed synchronous generators must follow the demands that have been placed, and one of them is the detection of isolated operation within the recommended time interval. By definition, the isolated operation occurs when the part of the distribution network becomes electrically separated from the rest of the grid, but remains powered by the distributed sources. The protection system of 
distributed synchronous generators must be able to follow the demands that have been placed, and one of them is the detection of isolated operation within the recommended time interval.

Supplying the isolated part of the system can cause a number of problems, both for the distributed generator and for the connected consumers. It can also endanger personnel responsible for maintaining the system considering that the system, after a failure, is in the voltage-free state after the disconnection of the switches. Therefore, all networks must include the protection of isolated operation. For this purpose, the relay is typically used for detection of the angle shift of voltage. All synchronous distributed generators are also equipped with under / over frequency relays.In the case of isolated operation, frequency and voltage are controlled by the turbine and excitation regulators whose dynamics are difficult to model in making EAA (Study Tuned Protection). Smaller generators are often not equipped with devices to control voltage; therefore the amount of power within the island network can have values greater or smaller than permitted. Frequency instability can also be a result of the island preformance. Tripping times of short-currentprotection are in the order of several hundred milliseconds. If there is "AR"-Automatic reclosing of the overhead linethat can cause problems if the generator is not protected against reverse power.Also, during the network separation there is active power imbalance, and thus the change in frequency. Automatic closing of the switch would mean connecting two asynchronous systems. In order to allow the removal of a fault, between the separation of the generator and reverse power occurring there must be a certain time lag. The usual time delay by the relay with the APU re-closing is between $100 \mathrm{~ms}$ and $1000 \mathrm{~ms}$ (for Croatian distribution system operator "HEP ODS"standard value is $300 \mathrm{~ms}$ or $400 \mathrm{~ms}$ ). The rate of change of frequency is expressed as a function of the imbalance of active power (1) and inertial constant generator $\mathrm{H}$, apparent power of the generator $S_{n}$ and frequency before the island operation $f_{s}(2)$.

$$
\begin{aligned}
& \Delta P=\sum P_{d g}-P_{i} \\
& \frac{d f}{d t}=\frac{\Delta P \cdot f_{s}}{2 \cdot S_{n} \cdot H}
\end{aligned}
$$

where:

$\Delta \mathrm{P}$ - active power debalance

$\mathrm{P}_{\mathrm{dg}}$ - output power of the generator

$\mathrm{P}_{\mathrm{i}}$ - power consumption in the insular part of the network

$\mathrm{f}_{\mathrm{s}}$ - frequency before the island's labor

$\mathrm{H}$ - constant inertia of the generator

$\mathrm{S}_{\mathrm{n}}$ - apparent power of the generator

From this we calculate the frequency change (3):

$$
\Delta f=\frac{\Delta P \cdot f_{s}}{2 \cdot S_{n} \cdot H} \cdot t_{i}
$$

This approach takes into account only the frequency change due to the island operation, but not a fault change of frequency. From the equation it is shown that if the experiment of isolated operation according to "PIPI" (Croatian abbreviation for Testing Plan and Program that is required by HEP ODS) is working with power imbalance $\Delta \mathrm{P}=0.00 \mathrm{~kW}$ or small imbalance of power between consumers and generation, there will be no change in frequency in such a short period of time, especially since the dynamics of the turbine and excitation regulator is not taken into account in the calculation. The protection of isolated operation is performed with SIEMENS numerical relay function ROCOF $\mathrm{df} / \mathrm{dt}>0.2 \mathrm{~Hz} / \mathrm{s}$, as the shift of vector voltage angle between generator and network $\Delta \theta>7^{\circ}$, as well as passive protection under/overvoltage, under/over frequency as shown in Table 4.

Table 4. Anti Islanding Protection Settings

\begin{tabular}{ccc}
\hline Function & Settings & Time Delay \\
\hline Undervoltage $\mathrm{U}<<$ & $0,85 \mathrm{Un}$ & $0.15 \mathrm{~s}$ \\
OvervoltageU $>>$ & $1.15 \mathrm{Un}$ & $0.15 \mathrm{~s}$ \\
Underfrequency f $\langle<$ & $49 \mathrm{~Hz}$ & $0,1 \mathrm{~s}$ \\
Overfrequency $\mathrm{f} \gg>$ & $51 \mathrm{~Hz}$ & $0,1 \mathrm{~s}$ \\
ROCOF df $/ \mathrm{dt}>$ & $0,2 \mathrm{~Hz} / \mathrm{s}$ & $0.2 \mathrm{~s}$ \\
Delta theta $\Delta \theta>$ & $7^{\circ}$ & $0,0 \mathrm{~s}$ \\
\hline
\end{tabular}

IJECE Vol. 6, No. 6, December 2016 : 2526 - 2537 
At time $\mathrm{t}=100 \mathrm{~ms}$ from the beginning of simulation, the circuit breaker in the field $\mathrm{J} 1$ - high voltage switchgear of power plant is simulated.

Experimantal measurments od electrical parameters during the starting of turbine-generator set are presented in Figure 11

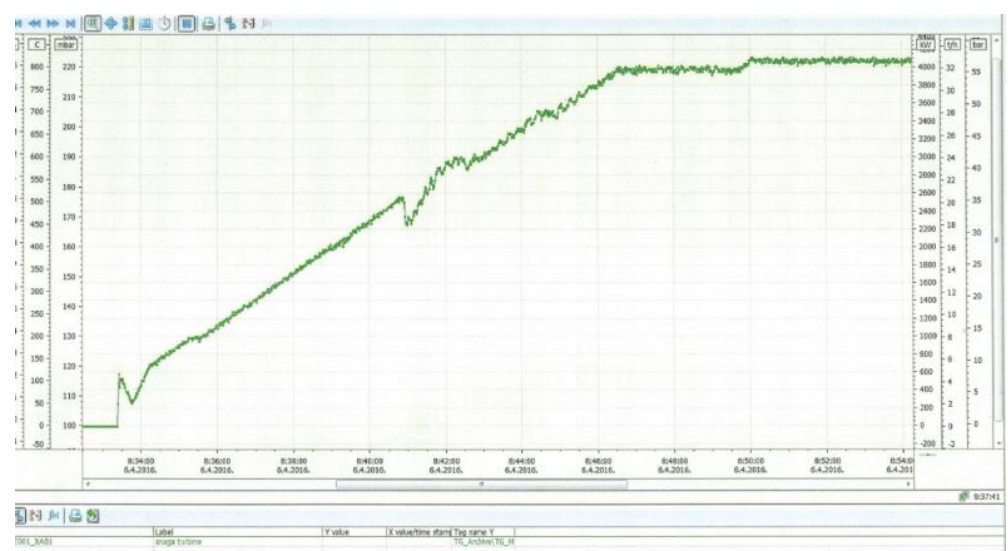

Figure 11. Experimantal Measurments od Electrical Parameters During the Starting of Turbine-Generator Set

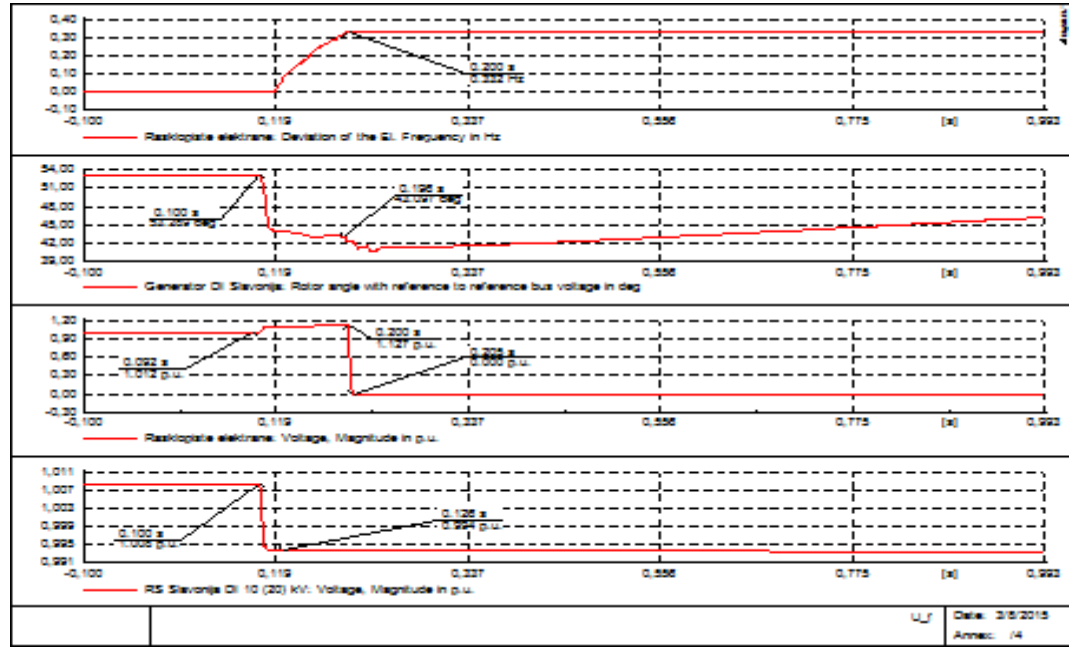

Figure 12. RMS Values of Frequency, Rotor Angle an Voltagres During Opening Generator Braker J1

The frequency deviation in the field $\mathrm{J} 2$ is shown on the first oscillogram in Figure 12; angle of the generator rotor in relation to the angle of voltage busbar is on the second oscillogram. The voltage on switchyard busbars of power plant is on the third oscillogram; voltage on busbars of Slavonia DI is on the fourth oscillogram.

\section{CONCLUSION}

The paper describes the process of simulation and coordination of short-circuit protection, under/over voltage, under/over frequency protections, as well as protection from isolated operation of biomass power plant rated power of $6 \mathrm{MVA}$, or $4.66 \mathrm{MW}$ active power in parallel operation with $35 \mathrm{kV}$ distribution network. The time-simulation is shown for various shortcircuit events and oscillograms of current, voltage, frequency, rotor angle and other important characteristics of the generator, adjacent switchyard and part of the distribution network of "HEP ODS" are presented. Iterative procedure resulted with proper coordination of all necessary protection devices in order for the plant to work properly on the network and to be protected fromfaults in the network and vice versa, in order to protect distribution network from faults and disturbances inthe power plant. 


\section{ACKNOWLEDGEMENTS}

We would like to thank the Slavonija OIE Company, especially to DarkoTakač, dipl.ing. for his technical support.

\section{REFERENCES}

[1] M. Zellagul, A. Changal, "Impact of RDG Location on IDMT Overcurrent Relay Operation and Coordination in MV Distribution System”, TELKOMNIKA Indonesian Journal of Electrical Engineering, Vol 12 No 11, 2014 pages 7585-7594.

[2] B, Yu, M. Matsui,G. Yu, "Passive Method for Distributed-Generation Island Detection Based on Oscillation Frequency“, IEEE Transactions on Power Delivery, Vol. 31, No. 1, February 2016.

[3] J.C.M. Vieira, W. Freitas, W. Xu and A. Morelato, "Performance of Frequency Relays for Distributed Generation Protection”, IEEE Transactions on Power Delivery, Vol. 21, No. 3, July 2006.

[4] A. Foss, K. Leppik, “A review of current anti-islanding methods for photovoltaic power system”, Solar Energy, 84 (2010) 745-754.

[5] N. Ghadimi, H. Ebrahimian, R. Ghadimi and A. Danandeh, "A New Active Method to Diagnose the Anti-Islanding Mode Protection for Photovoltaic System”, World Applied Sciences Journal, 15 (11): 1593-1597, 2011.

[6] S. Akhlaghi, A. Ghadimi. A Akhlaghi, "A Novel Hybrid Islanding Detection Method combination of SMS and Q-f for Islanding Detection of Inverter-Based DG", Conference Paper. February 2014, DOI: 10.1109/PECI.2014.6804571

[7] S. Kar, S.R. Samantaray, "Intelligent Anti-Islanding Protection Scheme for Distributed Generations", 2013 Annual IEEE India Conference, 978-1-4799-2275-8/13.

[8] F. Hashemia, A. Kazemib, S. Soleymaniam, "A New Algorithm to Detection of Anti-Islanding Based on dqo Transform”, Energy Procedia 14 (2012) 81 - 86.

[9] M. Bakhshi R. Noroozian, "Reactive Power Based Anti-islanding Scheme for Synchronous Distributed Generators", International Journal on "Technical and Physical Problems of Engineering”, December 2012 Issue 13 Volume 4 Number 4 Pages 30-37.

[10] J. Merino, P.M. Araya, G. Venkataramananmm M. Baysal, "Islanding Detection in Microgrids Using Harmonic Signatures", DOI 10.1109/TPWRD.2014.2383412, IEEE Transactions on Power Delivery.

[11] S. Nikolovski, P. Marić, Lj. Majdandžić, "Integration of Solar Power Plant in Distribution Network", International Journal of Electrical and Computer Engineering (IJECE), Vol. 5, No. 4, August 2015, pp. 656 668.

[12] HROTE website. [Online]. Available: http://www.hrote.hr/(2013).

[13] DIgSILENT Power Factory 15.01 User Manual, Gomaringen, 2015.

[14] EasyPower 9,7 version, User Maual, Easypower LCC, Tulatin, USA, 2014.

\section{BIOGRAPHIES OF AUTHORS}

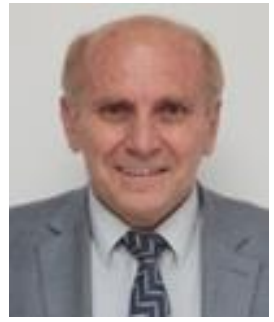

Srete Nikolovski, PhD. El. Eng. (IEEE M'1995, SM'2005) was born in Belgrade on October 1, 1954. He obtained his BSc degree (1978) and MSc degree (1989), in electrical engineering at the Faculty of Electrical Engineering, University of Belgrade and his $\mathrm{PhD}$ degree from the Faculty of Electrical and Computing Engineering, University of Zagreb, Croatia in 1993. Currently he is a Full Professor at Power Engineering Department at Faculty of Electrical Engineering computer science and information technology, J.J. Strossmayer University in Osijek, Croatia. His main interests are power system protection, power system modeling, simulation and reliability. He has published 180 technical papers in journals and international conferences. He is a Senior Member of IEEE Reliability Society, PES Society and the member of Croatian National Committee of CIGRE

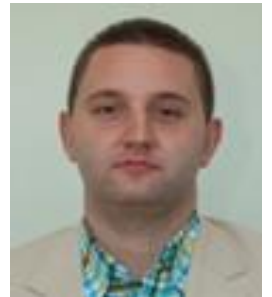

Marko Vukobratović, MEE, was born on 9 October 1985 in Osijek. He obtained Masters degree in 2012 in field of Electrical Power Engineering from the faculty of Electrical Engineering of Osijek. Currently he works as research assistantat the Power System Department at the Faculty of Electrical computer science and information technology in Osijek. At the same Faculty he is obtaining postgraduate studies. He is an author of 15 scientific and professional papers in the field of power engineering. His main interests are distributed generation, smart grids and power system optimization and control. He is a IEEE student member and member of Croatian National Committee of CIGRE. 


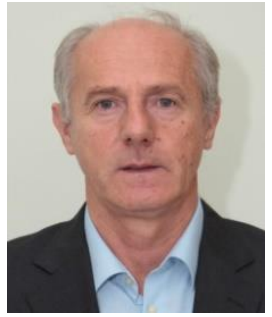

Ljubomir Majdnandžić PhD. Mech. Eng, was born on July 4, 1960 in Ivanjska at Banja Luka. He graduated two post studies: in 1999 at the Faculty of Mechanical Engineering and Naval Architecture University of Zagreb and in 2001 at the Faculty of Economics in Zagreb. From2001 to 2003 working on a doctorate at the Fraunhofer Institute for Solar Energy, Department ofelectric power systems, in Freiburg, Germany. At the Faculty of Electrical Engineering and Computing in Zagreb his $\mathrm{PhD}$ in 2004. He is currently general manager of The Environmental Protection and Energy Efficiency Fund. Author of 64 scientific and professional work in the field of energy, renewable energy and sustainable development. He is a member of the International Solar Energy Society (ISES), the German Society for Solar Energy (Deutsche Gesellschaft für Sonnenenergie eV DGS) and the Croatian Energy Association (HED). 